\title{
Voltammetric sensor based on magnetic particles modified composite electrode for determination of triamterene in biological sample
}

\author{
Felipe Fantinato Hudari ${ }^{1}$ - Bianca Ferreira da Silva ${ }^{1}$ - Maria Isabel Pividori ${ }^{2}$. \\ Maria Valnice Boldrin Zanoni ${ }^{1}$
}

Received: 1 October 2015 /Revised: 3 November 2015 / Accepted: 6 November 2015 /Published online: 17 November 2015

(C) Springer-Verlag Berlin Heidelberg 2015

\begin{abstract}
Some diuretic substances are controlled and monitored by the World Anti-Doping Agency as prohibited substances for use by athletes, such as triamterene (TRT). Thus, this work describes a voltammetric method based on graphiteepoxy composite electrode modified by tosyl-functionalized magnetic particles (GECE/MPs-To) for determination of TRT diuretic in urine sample. The TRT presented an oxidation peak at $+1.24 \mathrm{~V}$ at GECE/MPs-To with irreversible behavior. Controlled potential electrolysis of the TRT at $+1.26 \mathrm{~V}$ indicated the two electrons are transferred during amine group oxidation and the main product was identified by LC-MS/MS. The anodic peak current is $25 \%$ higher at the modified electrode, suggesting that TRT is adsorbed on the magnetic particles. Using optimized conditions by using multivariate optimization of the parameters inherent of the square wave voltammetry, a calibration curve was constructed with a linear relation-

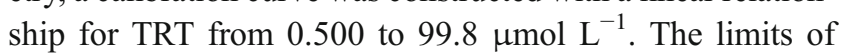
detection and quantification were 1.47 and $4.91 \times 10^{-7} \mathrm{~mol}$ $\mathrm{L}^{-1}$, respectively. The proposed method was applied to urine sample and validated by LC-MS/MS technique where the values found and compared between the two techniques showed no significant difference at $95 \%$ confidence.
\end{abstract}

Felipe Fantinato Hudari

felipe_fhudari@hotmail.com

1 Departamento de Química, UNESP, Universidade Estadual Paulista Júlio Mesquita Filho, Instituto de Química de Araraquara, Rua Francisco Degni, 55, Bairro Quitandinha,, 14800-900 Araraquara, SP, Brazil

2 Departamento de Química, Grupo de Sensor e Biosensor, Universidade Autônoma de Barcelona, Bellaterra, 08193 Barcelona, Spain
Keywords Magnetic particles · Triamterene · Diuretic . Graphite-epoxy composite electrode · Voltammetric sensor . Multivariate optimization

\section{Introduction}

The magnetic particles (MPs) have been overexploited as drug carrier materials, cancer therapy, hyperthermia, magnetic separation, magnetic resonance, catalysis, sensors, and biosensors [1-14]. As an example of the use of the MPs as biosensors, in the work of Lermo et al., the researchers proposed a biosensor based on the immobilization of the protein conjugate BSAfolic acid in magnetic beads functionalized with tosyl group and subsequent preconcentration using a composite electrode for the determination of folic acid in vitamin-fortified milk sample. Thus, through analysis in $0.01 \mathrm{~mol} \mathrm{~L}^{-1}$ phosphate buffer solution $(\mathrm{pH} 7.5)$, the detection limit and the linear relationship were $6 \mathrm{nmol} \mathrm{L}^{-1}$ and 18.1 to $323.9 \mathrm{nmol} \mathrm{L}^{-1}$ in phosphate buffer solution and $13.1 \mathrm{nmol} \mathrm{L}^{-1}$ and 21.1 to $129.3 \mathrm{nmol} \mathrm{L}^{-1}$ in milk reference solution, respectively [15]. Mani and co-authors also demonstrated that glassy carbon electrode modified with iron nanoparticles decorated with nanocomposites of graphene/multiwalled carbon nanotubes can successfully be used for determining nitrite in water samples. Under optimized conditions, the amperometric detection of nitrite occurs at $+0.77 \mathrm{~V}$ in $0.05 \mathrm{~mol} \mathrm{~L}^{-1}$ phosphate buffer solution (pH 5.0) reaching detection limit of $75.6 \mathrm{nmol} \mathrm{L}^{-1}$ [16].

In general, the most promising MPs are iron oxide particles that can be found in various types such as magnetite $\left(\mathrm{Fe}_{3} \mathrm{O}_{4}\right)$, maghemite $\left(\gamma-\mathrm{Fe}_{2} \mathrm{O}_{3}\right)$, and hematite $\left(\alpha-\mathrm{Fe}_{2} \mathrm{O}_{3}\right)[17,18]$. Among these, magnetite is most extensively studied due to their superparamagnetic behavior at room temperature. In addition to this characteristic, $\mathrm{Fe}_{3} \mathrm{O}_{4}$ is suitable for its 
incorporation into biological areas, because it has no toxicity, presents high biocompatibility, and is easy to be obtained such as: sol-gel, co-precipitation, hydrolysis, and thermal decomposition [19-22].

The interest in magnetite particles in electrochemical area is based on their easy use when applied to the modification of electrodes, high adsorption of analyte, and a large surface area, increasing the pre-concentration of the analyte of interest obtaining, thus, low levels of detection as described by several authors [23-25].

Bagheri et al. [24] have reported the use of magnetite/ carbon nanotube paste electrode for voltammetric determination of haloperidol. Using optimized conditions of $0.10 \mathrm{~mol} \mathrm{~L}^{-1}$ Britton-Robinson (B-R) buffer solution ( $\mathrm{pH}$ 7.5), the authors reached detection limits of $7.02 \times 10^{-10}$ and $1.33 \times 10^{-10} \mathrm{~mol} \mathrm{~L}^{-1}$ for differential pulse voltammetry (DPV) and square wave voltammetry (SWV), respectively. Yin et al. [25] have shown that a voltammetric sensor based on graphene, chitosan, and $\mathrm{Fe}_{3} \mathrm{O}_{4}$ nanoparticles modified glassy carbon electrode for the determination of guanine in urine sample. Linear calibration curves were obtained from $2.00 \times$ $10^{-6}$ to $3.50 \times 10^{-4} \mathrm{~mol} \mathrm{~L}^{-1}$ of guanine in $0.1 \mathrm{~mol} \mathrm{~L}^{-1}$ phosphate buffer solution ( $\mathrm{pH} 7.0)$.

Triamterene (Fig. 1) is a diuretic substance prohibited by the World Anti-Doping Agency (WADA) for athletes. Although it is widely used in hypertension treatments, combat of heart failure, cirrhosis, pulmonary disease, among others $[26,27]$, they are also used in order to increase the urinary flow while consequently decreasing the chance of detecting other illegal substances or even reducing the body weight of athletes [28]. By taking into account that competent toxicological trials in clinical and forensic toxicology usually require highly sensitive and selective analytical methods, the use of voltammetric sensor based on MPs could represent a great advantage.

The main analytical methods reported in literature for its determination are high-performance liquid chromatography [29], cloud point extraction combined with spectrofluorimetry [30], fluorescence spectroscopy [31], gas chromatography mass spectrometry [32], and electrochemical techniques [33, 34]. Nevertheless, there are few studies reporting the

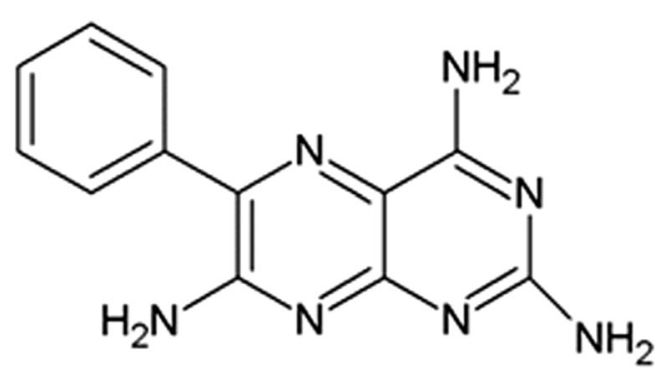

Fig. 1 Chemical structure of triamterene determination and quantification of this diuretic in biological samples such as blood or urine [35]. In the work of Ensafi and Hajian [34], the authors proposed an electroanalytical method using hanging mercury drop electrode for the determination of the triamterene and losartan in urine sample. Through analysis in $0.1 \mathrm{~mol} \mathrm{~L}^{-1} \mathrm{~B}-\mathrm{R}$ buffer solution $(\mathrm{pH} 3.0)$ using cathodic adsorptive stripping square wave voltammetric, a limit of detection of 9.70 and $0.300 \mathrm{nmol} \mathrm{L}^{-1}$ was found for losartan and triamterene, respectively. Therefore, the analytes were not found in the urine sample.

Thus, the present work aims to develop a sensor based on the tosyl group-functionalized magnetic particles modifying graphite-epoxy composite electrode for the determination of the diuretic assigned as triamterene (Fig. 1) in the urine sample. For this, the electrochemical oxidation mechanism and also the use of $2^{3}$ factorial design, Doehlert matrix, and multi-response methodology to improve the knowledge about the oxidation process and also to improve the detection of this pharmaceutical compound in the biological fluid were studied.

\section{Experimental}

\section{Reagents and equipments}

All chemicals used in this work were of analytical grade, and the solutions were prepared using ultra-pure water (Milli- $\mathrm{Q}^{\circledR}$ system, Millipore). Triamterene (purity $\geq 99.9 \%$ ) and dimethylsulfoxide were obtained from Sigma-Aldrich. Boric acid, phosphate acid, acetic acid, ammonium chloride, and potassium chloride were from Merck. Sodium hydroxide was obtained from Synth. Magnetic particles functionalized with tosyl group were obtained from Life Technologies ${ }^{\circledR}$. Standard solution of $0.01 \mathrm{~mol} \mathrm{~L}^{-1}$ of triamterene was prepared by dissolution in dimethylsulfoxide (DMSO), which was diluted afterwards in Britton-Robinson buffer (B-R) $0.10 \mathrm{~mol} \mathrm{~L}^{-1}$ used as supporting electrolyte. The B-R buffer was prepared by mixing appropriated amounts of $0.10 \mathrm{~mol} \mathrm{~L}^{-1}$ sodium hydroxide to orthophosphoric acid, acetic acid, and boric acid $\left(0.10 \mathrm{~mol} \mathrm{~L}^{-1}\right.$ in each) solution. Measurements of $\mathrm{pH}$ were carried out in a TECNOPON mPA $210 \mathrm{pH}-$ meter. The electrochemical experiments were carried out in a potentiostat/galvanostat Autolab PGSTAT302N controlled by the NOVA software, using three electrodes.

\section{Graphite-epoxy composite electrode modified by tosyl-functionalized magnetic particles}

The composite electrode was constructed by using a graphite powder and epoxy resin prepared according to a method described in literature [36, 37]. Graphite powder and epoxy resin (1:4) were mixed, and after forming a paste, a thin layer of the 
mixture was placed to a depth of $3 \mathrm{~mm}$ in a cylindrical PVC bat (6 $\mathrm{mm}$ i.d.) with an electrical contact to promote contact. A cylindrical magnet (3-mm diameter) was then placed into the center of this electrode, and the body of the electrode was filled with the paste. After filling, the electrode was tightly packed and maintained at rest at $40{ }^{\circ} \mathrm{C}$ for 1 week to obtain a rigid composite. After electrode preparation, a suspension of $30 \mathrm{mg} \mathrm{mL}^{-1}$ of magnetic particles functionalized with tosyl groups (MPs-To) was diluted in aqueous medium to generate a final solution of $1 \mathrm{mg} \mathrm{mL}^{-1}$. Next, $30 \mu \mathrm{L}$ of the suspension MPs-To was added to the surface of the composite electrode, which was used after evaporation of the solvent for $2 \mathrm{~h}$ at room temperature.

\section{Electrochemical analysis}

All electrochemical measurements were conducted in an electrochemical cell of $10.0 \mathrm{~mL}$ in a conventional system threeelectrode containing the work (composite electrode with and without modification by MPs-To), auxiliary (platinum wire), and reference $\left(\mathrm{Ag} \mid \mathrm{AgCl} ; \mathrm{KCl}, 3 \mathrm{~mol} \mathrm{~L}^{-1}\right)$ electrodes. After modification of the composite electrode with MPs-To, the electrode was subjected to several electrochemical cycling from 0.8 to $1.4 \mathrm{~V}$ in $0.10 \mathrm{~mol} \mathrm{~L}^{-1} \mathrm{~B}-\mathrm{R}$ buffer solution $(\mathrm{pH}$ $6.0)$.

Controlled potential electrolysis of triamterene (TRT) diuretic was carried out in an electrochemical cell of $75.0 \mathrm{~mL}$ containing the work (platinum mesh), auxiliary (Ti/Ru sheet of $\left.25 \mathrm{~cm}^{2}\right)$, and reference $\left(\mathrm{Ag} \mid \mathrm{AgCl} ; \mathrm{KCl}, 3 \mathrm{~mol} \mathrm{~L}^{-1}\right)$ electrodes in $0.10 \mathrm{~mol} \mathrm{~L}^{-1} \mathrm{~B}-\mathrm{R}$ buffer solution ( $\mathrm{pH}$ 6.0). For these curves of current vs time, a fixed potential of $1.26 \mathrm{~V}$ was applied, when the flat current was obtained.

\section{LC-MS/MS analysis}

Analysis of LC-MS/MS for TRT diuretic and generated electrolyzed products after $3 \mathrm{~h}$ at $+1.26 \mathrm{~V}$ was performed in a high-performance liquid chromatography of 1200 Agilent Technologies coupled to a Mass Spectrometer 3200 QTRAP (Quadrupole Linear Ion Trap LC-ESI-MS/MS) equipped with a Phenomenex Kinetex PFP column $(150 \times 4.6 \mathrm{~mm} ; 5 \mu \mathrm{m})$. The analysis conditions were based on Murray and Danaceau with some modifications [38]. Sample elution was performed using a gradient mode of a mixture of ultra-pure water containing $0.10 \%$ formic acid (A) and methanol (B). For the analysis of the TRT degradation, the following gradient programming was used: $0-2 \min 5 \% \mathrm{~B}, 2-12 \min 5-100 \% \mathrm{~B}$, $12-13 \min 100 \% \mathrm{~B}, 13-14 \mathrm{~min} 100-5 \% \mathrm{~B}$, and $14-20 \mathrm{~min}$ $5 \% \mathrm{~B}$, using the flow rate of $1 \mathrm{~mL} \mathrm{~min}^{-1}$ and sample injection volume of $20 \mu \mathrm{L}$.

The ion source was operated in an electrospray positive mode at $600{ }^{\circ} \mathrm{C}$ in the following conditions of ionization: ion spray voltage $(\mathrm{IS})=5500 \mathrm{~V}$; curtain gas $(\mathrm{CUR})=20 \mathrm{psi}$; nebulizer gas $_{1}=50 \mathrm{psi}$; nebulizer gas $_{2}=50 \mathrm{psi}$; declustering potential (DP), $31 \mathrm{~V}$; and entrance potential (EP), $10 \mathrm{~V}$.

The experiments for the investigation of the oxidation products were performed by software LightSight ${ }^{\circledR}$ (SCIEX), where a series of pre-programmed reactions were investigated based on the fragment ion spectrum of the TRT standard. All the experiments were tested by enhanced mass scan (EMS), and selected reaction monitoring (SRM) with simultaneous acquisition of fragment ion experiments was performed.

\section{Urine samples}

The method was applied in the analysis of TRT diuretic in human urine sample using the following procedure: $10 \mathrm{~mL}$ of urine sample was collected from a healthy person who volunteered, which was spike to $4.93 \mu \mathrm{mol} \mathrm{L}{ }^{-1}$ of TRT. Two milliliters of this sample was diluted in $8 \mathrm{~mL}$ of $0.10 \mathrm{~mol} \mathrm{~L}^{-1} \mathrm{~B}-\mathrm{R}$ buffer solution ( $\mathrm{pH}$ 6.0) in the electrochemical cell and analyzed without any pretreatment of the sample.

The validation of the proposed method was obtained using analyzes of TRT in the same sample by using LC-MS/MS, after previous dilution of five times and sample cleaning. The sample pretreatment was performed using $2 \mathrm{~mL}$ of the urine spiked to TRT and submitted to an extraction step in a Phenomenex Strata-X $33 \mathrm{u}$ cartridge ( $200 \mathrm{mg}, 3 \mathrm{~mL}$ ), previously conditioned with methanol $(3 \mathrm{~mL})$ and Milli-Q water $(3 \mathrm{~mL})$. After sample loading, the sorbent was washed with $2 \mathrm{~mL}$ of Milli-Q water. After drying for 1 min under nitrogen gas flow, the analyte was eluted with $2 \mathrm{~mL}$ methanol and then an aliquot $(150 \mu \mathrm{L}$ of sample $+150 \mu \mathrm{L}$ of Milli-Q water) was inserted in vials for analysis in the LC-MS/MS.

The LC-MS/MS methodology was performed using a selected reaction monitoring (SRM) experiment, where three transitions of the compound were monitored from the standard optimization by direct infusion at the concentration of $0.10 \mathrm{ppm}$ to $10 \mu \mathrm{L} \min ^{-1}$. The parameters of SRM were monitored (Table 1)

Ionizations in a positive mode condition were the same as described in "LC-MS/MS analysis." For the LC analysis, the same mobile phase was used, however, with a different gradient elution: $0-2 \min 30 \% \mathrm{~B}, 2-4 \min 100 \% \mathrm{~B}, 4-5 \mathrm{~min}$ $100 \% \mathrm{~B}, 5-6 \min 100-70 \% \mathrm{~B}$, and $6-10 \min 70 \% \mathrm{~B}$. The

Table 1 Parameters of SRM

\begin{tabular}{llll}
\hline $\begin{array}{l}\text { Precursor } \\
\text { ion (Q1) }\end{array}$ & $\begin{array}{l}\text { Fragment } \\
\text { ion (Q3) }\end{array}$ & $\begin{array}{l}\text { Collision } \\
\text { energy (V) (CE) }\end{array}$ & $\begin{array}{l}\text { Cell exit potential } \\
(\mathrm{V})(\mathrm{CXP})\end{array}$ \\
\hline $254>$ & 237 & 23 & 4 \\
$254>$ & 104 & 51 & 4 \\
$254>$ & 141 & 55 & 4 \\
\hline
\end{tabular}


flow rate was $1 \mathrm{~mL} \min ^{-1}$ and sample injection volume of $20 \mu \mathrm{L}$.

\section{Results and discussion}

\section{Electrochemical oxidation of TRT}

Cyclic voltammograms obtained for $100 \mu \mathrm{mol} \mathrm{L} \mathrm{L}^{-1}$ triamterene in $0.10 \mathrm{~mol} \mathrm{~L}^{-1} \mathrm{~B}-\mathrm{R}$ buffer, $\mathrm{pH} 4.0$, at the composite electrode before (curve a) and after (curve b) modification with magnetic particles functionalized with tosyl group are shown in Fig. 2(I). An anodic peak is observed at $1.30 \mathrm{~V}$ (without) and at $1.24 \mathrm{~V}$ (with modification), and no cathodic peak is observed at reverse scan. The anodic peak increased $25 \%$ at the modified electrode, suggesting that the TRT is preconcentrated on the electrode surface. This behavior can be assigned due to the hydrogen bonds between the hydrogen of the amine of the molecule of TRT with the sulfone group present in the molecule of the tosyl group.

The effect of the successive cycles on the voltammograms recorded for TRT using graphite-epoxy composite electrode modified by tosyl-functionalized magnetic particles (GECE/MPs-To) is shown in Fig. 2(II). It is observed that that anodic peak decreases dramatically after the first scan, indicating that the oxidation product of the TRT also adsorbs on the electrode surface. The spontaneous adsorption is very fast, since there was no current increased when accumulation time (0-5 min) was studied. However, to minimize problems and surface renewal, prior to analysis, the solution was stirred for $20 \mathrm{~s}$ to remove the oxidized species, when the peak intensity is completely recovered.

\section{The scan rate effect of oxidation of TRT}

The effect of the scan rate ( ) in the anodic peak $\left(I_{\text {ap }}\right)$ intensity was investigated from 5.00 to $200 \mathrm{mV} \mathrm{s}^{-1}$ for $100 \mu \mathrm{mol} \mathrm{L}^{-1}$ of TRT in $0.100 \mathrm{~mol} \mathrm{~L}^{-1} \mathrm{~B}-\mathrm{R}$ buffer solution. The $I_{\text {ap }}$ increased according to a linear relationship with equation $I_{\mathrm{ap}}=(5.54 \pm$
$0.18) \times 10^{-5}+(10.0 \pm 1.7) \times 10^{-7}\left(R^{2}=0.990\right)$. This behavior is an indicative that the charge transfer is controlled by adsorptive process [39].

The active area of the modified electrode was calculated by the Randles-Sevcik equation $\left(I_{\mathrm{ap}}=2.69 \times 10^{5} n^{3 / 2} A D_{0}^{1 / 2} C_{0} v^{1 / 2}\right)$ [39], where, $I_{\mathrm{ap}}$ is the intensity of the anodic peak $(\mu \mathrm{A}), n$ is number of electron, $A$ is the active area of the electrode $\left(\mathrm{cm}^{2}\right)$, $D_{0}$ is the diffusion coefficient $\left(\mathrm{cm}^{2} \mathrm{~s}^{-1}\right), v^{1 / 2}$ is the square root of the scan rate $\left(\mathrm{V} \mathrm{s}^{-1}\right)$, and $C_{0}$ is the analyte concentration $\left(\mathrm{mol} \mathrm{cm}{ }^{-3}\right)$. The active area for the GECE/MPs-To was estimated as $0.167 \mathrm{~cm}^{2}$, taking cyclic voltammograms recorded for $1.00 \mathrm{mmol} \mathrm{L}^{-1}$ potassium hexacyanoferrate (III) as model compound in $1.00 \mathrm{~mol} \mathrm{~L}^{-1} \mathrm{KCl}$ solution (diffusion coefficient $=7.60 \times 10^{-6} \mathrm{~cm}^{2} \mathrm{~s}^{-1}$ ) [39]. The diffusion coefficient for TRT was $3.50 \times 10^{-6} \mathrm{~cm}^{2} \mathrm{~s}^{-1}$, obtained from Randles-Sevcik (for irreversible process $I_{\mathrm{ap}}=2.99 \times 10^{5} \alpha^{1 / 2} n^{3 / 2} A D_{0}^{1 / 2} C_{0} v^{1 / 2}$ ) equation [39] and the respective voltammograms for $100 \mu \mathrm{mol} \mathrm{L}{ }^{-1}$ of TRT between 5 and $100 \mathrm{mV} \mathrm{s}^{-1}$ in $0.100 \mathrm{~mol} \mathrm{~L}^{-1} \mathrm{~B}-\mathrm{R}$ buffer ( $\mathrm{pH}$ 6.0).

In order to find out the surface excess of diuretic on GECE/MPs-To, analysis for $100 \mu \mathrm{mol} \mathrm{L}{ }^{-1}$ of the analyte was carried in the range of scan rate of 20 to $75 \mathrm{mV} \mathrm{s}^{-1}$. From equation $I_{\text {ap }}=\frac{\alpha F^{2} A v \Gamma}{2.718 R T}$ [39],where , $A$, and $I_{\text {ap }}$ are the scan rate, the electrode active area of electrode, and the current peak, respectively, and other symbols have their usual meanings, the concentration of TRT at the surface of the GECE/MPs-To is $3.18 \times 10^{-10} \mathrm{~mol} \mathrm{~L}^{-1}$. The electron transfer coefficient $(\alpha)$ can be calculated from $n \alpha=\frac{47.7 \mathrm{mV}}{\left(E_{\mathrm{ap}}-E_{1 / 2}\right)}[39]$ taken from the cyclic voltammograms that indicate value of $n \alpha=1.68$. Knowing that the value of $n$ is 2 (sections "The effect of $\mathrm{pH}$ on oxidation of TR" and "Controlled potential electrolysis of the TRT"), the value of $\alpha$ is 0.84 .

\section{The effect of pH on oxidation of TRT}

The effect of $\mathrm{pH}$ on oxidation of $100 \mu \mathrm{mol} \mathrm{L}{ }^{-1}$ of TRT in $0.10 \mathrm{~mol} \mathrm{~L}^{-1} \mathrm{~B}-\mathrm{R}$ was evaluated from $\mathrm{pH} 4$ to 9 . Higher $\mathrm{pH}$ value promotes the diuretic deprotonation resulting in the
Fig. 2 Cyclic voltammograms for $100 \mu \mathrm{mol} \mathrm{L}^{-1}$ of TRT in $0.10 \mathrm{~mol} \mathrm{~L}^{-1} \mathrm{~B}-\mathrm{R}$ buffer solution (pH 4.0) using GECE $(a)$ and GECE/MPs-To $(b)(I)$ and cyclic voltammograms successive for $100 \mu \mathrm{mol} \mathrm{L}^{-1}$ of TRT in $0.10 \mathrm{~mol} \mathrm{~L}^{-1} \mathrm{~B}-\mathrm{R}$ buffer solution (pH 6.0) using GECE/MPs-To (II). Scan rate, $75 \mathrm{mV} \mathrm{s}^{-1}$
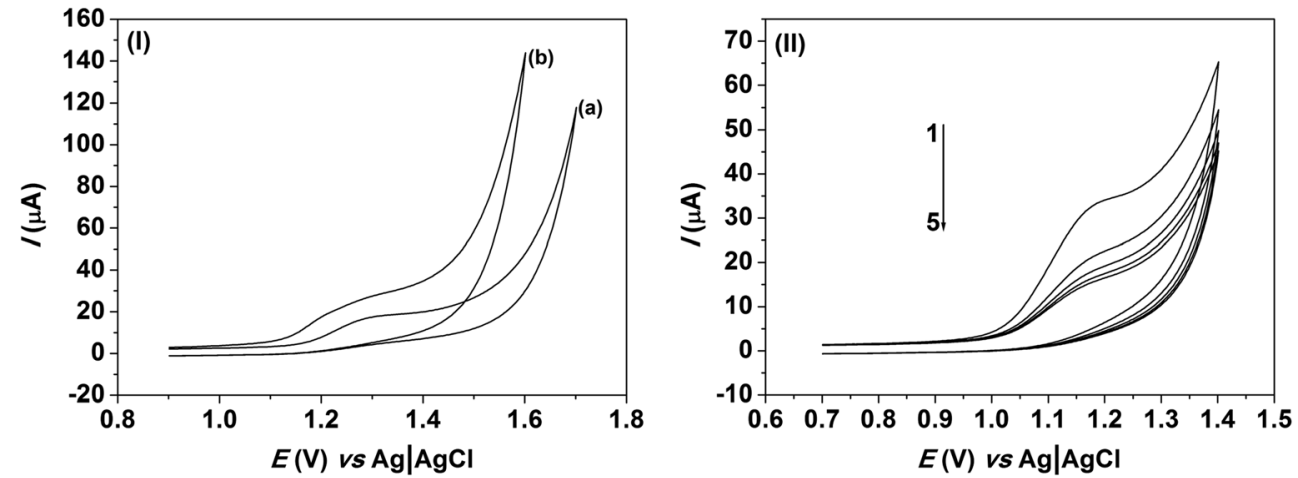
decreased of hydrogen bonds between the analyte and the MPs-To. Higher current intensity was found at $\mathrm{pH} 6$ coupled to better peak resolution, which was chosen at further studies. In addition, a shifting of anodic peak potential $\left(E_{\text {ap }}\right)$ to more negative potentials was observed, whose slope is $-59 \mathrm{mV} / \alpha n$, suggesting that the ratio of $\mathrm{e}^{-} / \mathrm{H}^{+}$for oxidation of TRT is around 1 [39]. In agreement with the predict for irreversible process with analyte adsorption [40], $E_{\text {ap }}=E^{0}-\left(\frac{\mathrm{RT}}{\alpha \mathrm{nT}}\right) \ln \left(\frac{\mathrm{RTk}_{\mathrm{s}}}{\alpha_{\mathrm{n}}}\right)+\left(\frac{\mathrm{RT}}{\alpha \mathrm{nF}}\right)$ $\ln \mathrm{v}$, where $\alpha$ is the coefficient of electron transfer, $k_{\mathrm{s}}$ the heterogeneous electron transfer rate constant, $n$ the number of electrons transferred, the scan rate, and $E^{0}$ is the formal redox potential. Thus, the term $\alpha n$ can be obtained by the slope of the relationship between $E_{\text {ap }}$ vs $\ln$. Substituting the values of $E_{\mathrm{ap}}$ vs $\ln$ (0.0157), $R$ (8.314), $T$ (298), and $F(96,480)$, the $\alpha n$ is equal to 1.63 . So, knowing that the value of $\alpha$ is equal to 0.84 , the number of electrons that participate in the oxidation process of TRT is $1.95(n=2)$, confirming the value found in section "Controlled potential electrolysis of the TRT." Thus, as the proportion of $\mathrm{e}^{-} / \mathrm{H}^{+}$is the same, the amount of protons that participate in reaction is equal to 2 . In order to obtain more details about the electrochemical oxidation of TRT, further studies were carried out using controlled potential electrolysis.

\section{Controlled potential electrolysis of the TRT}

The oxidations were carried out for $100 \mu \mathrm{mol} \mathrm{L}{ }^{-1}$ of the TRT in $0.10 \mathrm{~mol} \mathrm{~L}^{-1} \mathrm{~B}-\mathrm{R}$ buffer solution $(\mathrm{pH}$ 6.0) using a $\mathrm{Pt}$ electrode. The electrolysis was performed at a potential more positive than the oxidation peak recorded on this electrode (+ 1.26 V vs Ag/AgCl) during $3 \mathrm{~h}$. The current was recorded as a function of time, and the number of electrons $(n)$ consumed in the total oxidation was determined. The current decays exponentially with time and the $n$ values obtained are around two electrons (valor real \pm 0.220 with three repetitions).

At the end of the electrolysis, the products at the anode were examined by LC-MS/MS in agreement with the procedure described in experimental section. The total ion chromatogram (TIC) of the control sample (TRT solution before electrolysis) showed a peak at $7.9 \mathrm{~min}$ (Fig. 3a) with $\mathrm{m} / \mathrm{z} 254$ corresponding to TRT (MW. $253 \mathrm{Da},[\mathrm{M}+\mathrm{H}]^{+}$) (Fig. 3b). The same analysis was performed with the electrolysis sample and as observed at Fig. 3d, the TRT was still present $(\mathrm{m} / \mathrm{z} 254$ at retention time of $8.0 \mathrm{~min})$, and another peak was detected at 8.9 min with $m / \mathrm{z} 252\left([\mathrm{M}+\mathrm{H}]^{+}\right)$(Fig. 3e). The mass difference of 2.0 Da observed confirmed the oxidation product of TRT. $\mathrm{MS}^{2}$ experiments were also performed for both compounds. The TRT fragment ion spectra (Fig. 3c) showed $m / z 237$ corresponding to the loss of $17 \mathrm{Da}\left(-\mathrm{NH}_{3}\right), m / z 212$ (loss of
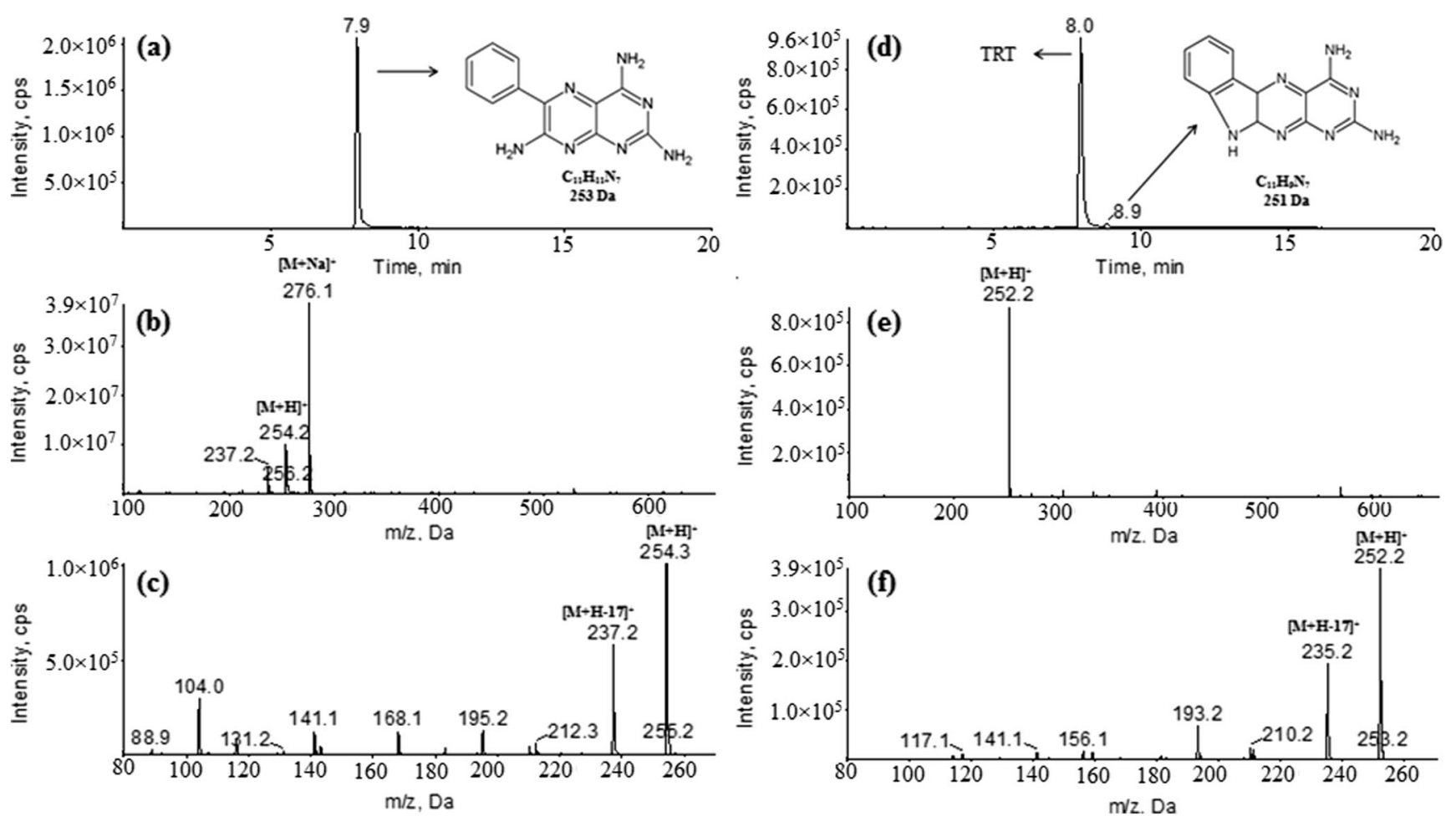

Fig. 3 a TIC of control sample. (b) Mass spectra of 7.9-min peak detected in (a). c Fragment ion spectra of $m / z$ 254. d TIC of electrolysis sample. e Mass spectra of 8.9-min peak detected in (d). f Fragment ion spectra of $\mathrm{m} / \mathrm{z} 252$ 
Table 2 Parameter, levels, and results of the $2^{3}$ factorial design

\begin{tabular}{|c|c|c|c|c|c|c|c|c|}
\hline \multicolumn{3}{|c|}{ Parameter } & \multicolumn{2}{|c|}{$\begin{array}{l}\text { Minimum } \\
(-)\end{array}$} & \multicolumn{2}{|c|}{ Central Point (0) } & \multicolumn{2}{|c|}{ Maximum (+) } \\
\hline$f(\mathrm{~Hz}$ & & & 30 & & 55 & & 80 & \\
\hline$E_{\mathrm{sw}}$ & $\mathrm{mV}$ ) & & 2 & & 6 & & 10 & \\
\hline$\Delta E($ & $\mathrm{nV)}$ & & 10 & & 55 & & 100 & \\
\hline Exp. & $E_{\mathrm{sw}}$ & $\Delta E$ & $f$ & $I_{\text {ap }}(\mu \mathrm{A})$ & B.L. $(\mu \mathrm{A})$ & $d i I_{\mathrm{ap}}$ & $d i$ B.L. & O.D. \\
\hline 1 & + & + & + & 116 & 280 & 1.000 & 0.000 & 0.000 \\
\hline 2 & - & + & + & 39.5 & 162 & 0.278 & 0.435 & 0.348 \\
\hline 3 & + & - & + & 31.6 & 44.0 & 0.204 & 0.869 & 0.421 \\
\hline 4 & - & - & + & 20.1 & 19.8 & 0.097 & 0.958 & 0.305 \\
\hline 5 & + & + & - & 49.5 & 110 & 0.372 & 0.626 & 0.483 \\
\hline 6 & - & + & - & 14.6 & 49.0 & 0.046 & 0.851 & 0.197 \\
\hline 7 & + & - & - & 28.0 & 19.5 & 0.171 & 0.959 & 0.405 \\
\hline 8 & - & - & - & 9.74 & 8.50 & 0.000 & 1.000 & 0.000 \\
\hline $9^{\mathrm{a}}$ & 0 & 0 & 0 & 50.5 & 98.0 & 0.382 & 0.670 & 0.506 \\
\hline $9^{\mathrm{a}}$ & 0 & 0 & 0 & 54.2 & 101 & 0.416 & 0.659 & 0.524 \\
\hline $9^{\mathrm{a}}$ & 0 & 0 & 0 & 52.5 & 99.0 & 0.400 & 0.667 & 0.517 \\
\hline $9^{\mathrm{a}}$ & 0 & 0 & 0 & 51.9 & 100 & 0.395 & 0.663 & 0.512 \\
\hline $9^{\mathrm{a}}$ & 0 & 0 & 0 & 50.9 & 99.0 & 0.386 & 0.667 & 0.507 \\
\hline
\end{tabular}

$f$ frequency, $E_{\mathrm{sw}}$ step potential, $\Delta E$ pulse amplitude

${ }^{\text {a }}$ Replicas of the central point

$42 \mathrm{Da},-\mathrm{NCNH}_{2}$ ), and $\mathrm{m} / z 195$ (loss of $59 \mathrm{Da},-\mathrm{NH}_{3}$ and $-\mathrm{NCNH}_{2}$ ); the same losses were observed to the oxidation product as the fragments obtained were $m / z 235,210$, and 193 (Fig. 3f). The high similarity between both spectra has led to the proposal of the structure found at Fig. $3 \mathrm{~d}$.

\section{Electroanalytical determination of TRT}

In order to obtain TRT low detection levels besides the use of GECE/MPs-To, the performance of linear scan, differential pulse, and square wave voltammetric techniques were

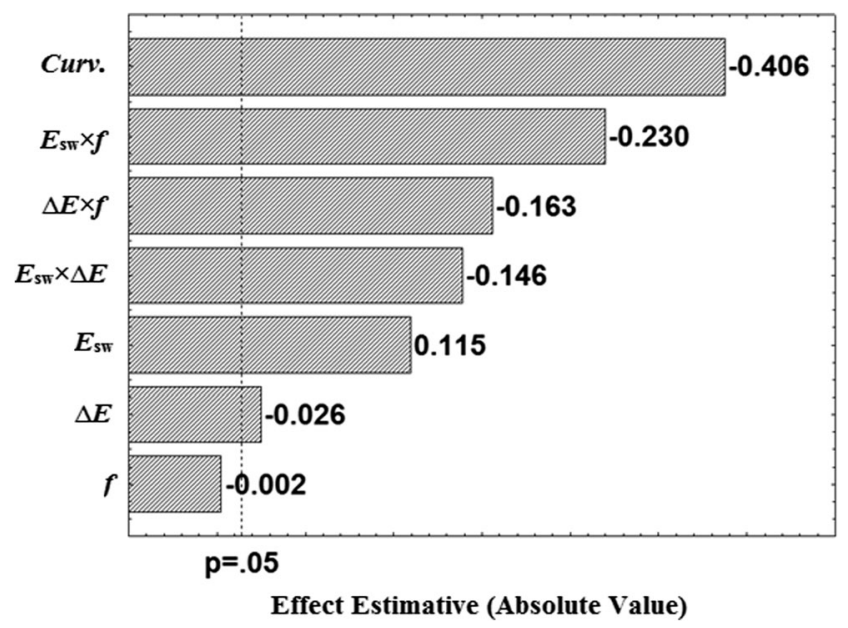

Fig. 4 Pareto diagram of the responses obtained in the $2^{3}$ factorial design compared. For this, voltammograms were recorded for $100 \mu \mathrm{mol} \mathrm{L}{ }^{-1}$ of TRT in $0.10 \mathrm{~mol} \mathrm{~L}^{-1} \mathrm{~B}-\mathrm{R}$ buffer solution (pH 6.0). The peak current intensity increased almost 44 and $85 \%$ for the square wave voltammetry compared to linear scan voltammetry and differential pulse voltammetry, respectively. Thus, the square wave technique was chosen for the quantification of the diuretic.

The parameters of square wave voltammetry technique were optimized aiming at determining of TRT through the $2^{3}$ factorial design, Doehlert matrix, and multi-response methodology [41-43]. The analytical signals ( $I_{\mathrm{ap}}$ and base line) from the $2^{3}$ factorial design, designated overall desirability, as well as their parameters and levels are shown in Table 2. Besides the experiments from the $2^{3}$ factorial design, the central point was included in the planning in order to analyze the behavior between the minimum points $(-)$ and maximum (+). To calculate the overall desirability of each experiment, individual desirabilities (di) were determined. The individual desirability is expressed as a dimensionless value ranging from 0 (undesired response) to 1 (desired response). Since the objective is to maximize $I_{\text {ap }}$, individual desirability for each experiment can be calculated using the following equation:

$d i_{I_{\text {ap }}}=\frac{(y-L)}{(H-L)}$

where $y$ is the value obtained experimentally, $L$ is the lowest value obtained among all experiments performed, and $H$ is the highest value obtained from all the

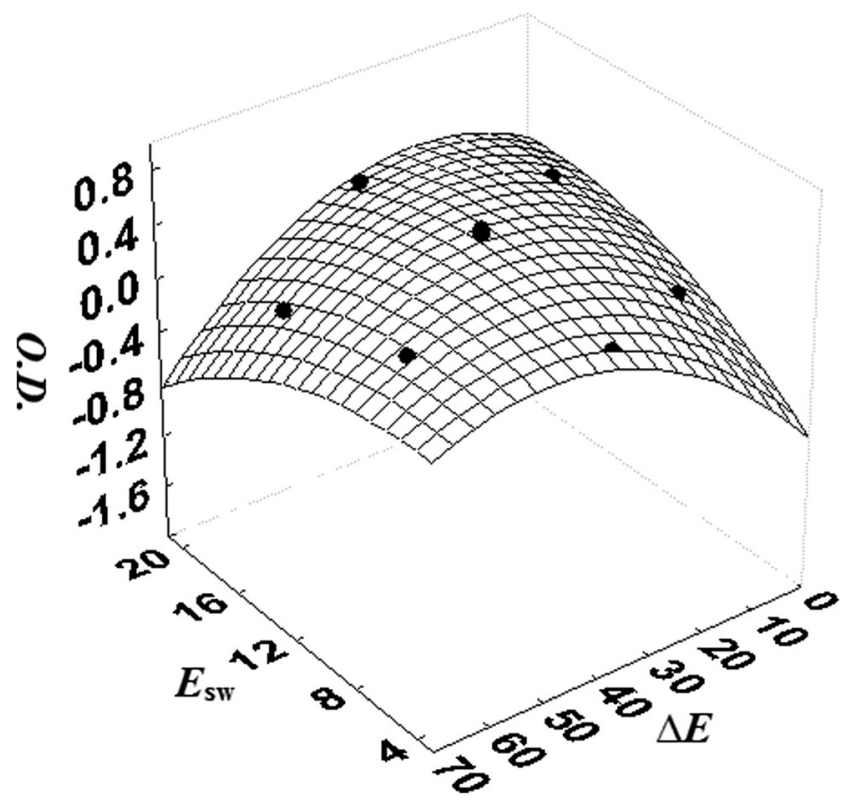

Fig. 5 Response surfaces for $E_{\mathrm{sw}} \times \Delta E$ 
Table 3 Doehlert matrix used for optimizing $E_{\mathrm{sw}}$ and $\Delta E$

\begin{tabular}{llllllll}
\hline Exp. & $E_{\mathrm{sw}}(\mathrm{mV})$ & $\Delta E(\mathrm{mV})$ & $I_{\mathrm{pa}}(\mu \mathrm{A})$ & B.L. $(\mu \mathrm{A})$ & $d i I_{\mathrm{pa}}$ & di B.L. & O.D. \\
\hline 1 & $12(0)$ & $35(0)$ & 53.5 & 52.5 & 0.593 & 0.487 & 0.537 \\
1 & $12(0)$ & $35(0)$ & 50.6 & 53.0 & 0.549 & 0.479 & 0.513 \\
1 & $12(0)$ & $35(0)$ & 48.5 & 52.6 & 0.517 & 0.485 & 0.501 \\
1 & $12(0)$ & $35(0)$ & 47.5 & 52.6 & 0.502 & 0.483 & 0.492 \\
1 & $12(0)$ & $35(0)$ & 46.0 & 52.7 & 0.480 & 0.484 & 0.482 \\
2 & $20(1)$ & $35(0)$ & 44.4 & 74.8 & 0.455 & 0.181 & 0.287 \\
3 & $16(0.5)$ & $60(0.866)$ & 80.6 & 88.2 & 1.000 & 0.000 & 0.000 \\
4 & $4(-1)$ & $35(0)$ & 21.1 & 29.7 & 0.106 & 0.799 & 0.291 \\
5 & $8(-0.5)$ & $10(-0.866)$ & 14.1 & 15.0 & 0.000 & 1.000 & 0.000 \\
6 & $16(0.5)$ & $10(-0.866)$ & 19.6 & 24.4 & 0.083 & 0.871 & 0.268 \\
7 & $8(-0.5)$ & $60(0.866)$ & 35.0 & 64.0 & 0.314 & 0.329 & 0.322 \\
\hline
\end{tabular}

experiments analyzed. However, to the base line (B.L.), the smaller value is a better response; thereby, the calculation of the individual desirability for this response may be made using Eq. 2:

$d i_{\text {B.L. }}=\frac{(H-y)}{(H-L)}$.

Thus, possession of the individual desirabilities, the overall desirability (O.D.) was determined by the geometric mean of individual desirabilities, as shown in Eq. 3:

O.D. $=\sqrt{\left(d i_{I_{\text {ap }}}\right)\left(d i_{\mathrm{B} . \mathrm{L} .}\right)}$.

The responses in O.D. were used for statistical treatment. As shown in Fig. 4, all parameters and interactions presented negative effect except the parameter $E_{\mathrm{sw}}$. This indicates that the best answers are obtained when the parameters $\Delta E$ and $f$ are at their lowest levels, while for the parameter $E_{\mathrm{sw}}$, the best answer was observed at their highest level. At the $95 \%$ significance level, the effect of all interactions and parameters was significant except for the parameter $f$ that was not significant for the method.
Among all the results shown in the Pareto diagram, the curvature (Curv.) was the most significant study to the work. The Curv. is given by the following equation [44]:

Curv. $=R_{\mathrm{ed}}-R_{\mathrm{cp}}$,

where $R_{\text {ed }}$ is the average responses obtained from experiments specified by the factorial design and $R_{\mathrm{cp}}$ is the average responses obtained for the central point. Thus, a positive value indicates that the best answers are acquired for the points belonging to the factorial design while a negative value for the Curv. indicates that best results are found for the points near the central point. Thus, as shown in Fig. 5, the effect for the Curv. presented a negative result, indicating that the best responses are obtained for values of the center point. Since the parameters $E_{\mathrm{sw}}$ and $\Delta E$ were significant for the method, a more detailed study was carried by Doehlert matrix. As $f$ showed no significance for the method at level $95 \%$, the frequency was set at its lowest level $(30 \mathrm{~Hz})$, where the best responses were obtained.

For Doehlert matrix, the same analytical responses were used ( $I_{\mathrm{ap}}$ and B.L.). Thus, the responses were converted in terms of $d i$ according to Eqs. 1 and 2 and then in O.D.

Table 4 ANOVA for the results obtained of the Doehlert matrix

\begin{tabular}{lllll}
\hline Factor & Square sum (SS) & Degrees of freedom (d.f.) & Mean square (MS) \\
\hline$E_{\text {sw }}{ }^{2}$ & 0.000314 & 1 & 0.000314 & 0.692 \\
$E_{\text {sw }}{ }^{2}$ & 0.0667 & 1 & 0.0667 & 147 \\
$\Delta E$ & 0.000716 & 1 & 0.000716 & 1.58 \\
$\Delta E^{2}$ & 0.234 & 1 & 0.234 & 516 \\
$E_{\text {sw }} \times \Delta E$ & 0.0870 & 1 & 0.0870 & 192 \\
lack of fit & 0.000410 & 1 & 0.000410 & 0.904 \\
pure error & 0.00181 & 4 & 0.000454 \\
Total & 0.380 & 10 & & \\
\hline
\end{tabular}




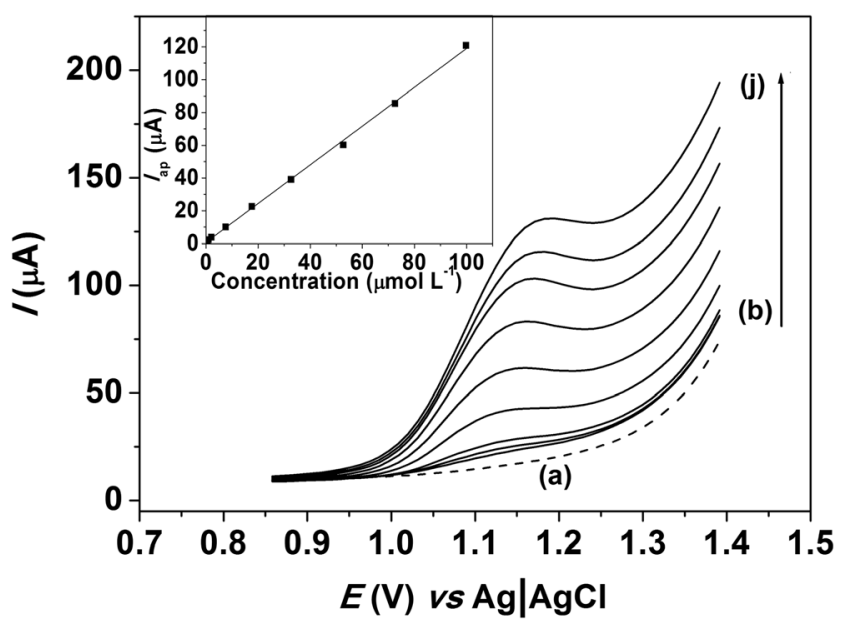

Fig. 6 Square wave voltammograms in $0.10 \mathrm{~mol} \mathrm{~L}^{-1} \mathrm{~B}-\mathrm{R}$ buffer solution ( $\mathrm{pH}$ 6.0) for supporting electrolyte $(a)$ and for the concentrations of $0.500(b), 1.00(c), 2.00(d), 7.60(e), 17.6(f), 32.7$ $(g), 52.7(h), 72.6(i)$, and $99.8 \mu \mathrm{mol} \mathrm{L}{ }^{-1}(j)$ for TRT. Respective analytical curve obtained for $I_{\text {ap }}$ vs [TRT] (insert). $f: 30 \mathrm{~Hz}, \Delta E$ : $36.2 \mathrm{mV}, E_{\mathrm{sw}}: 11.5 \mathrm{mV}$

(Eq. 3). The results of Doehlert matrix are shown in Table 3. Through analysis of variance (ANOVA), it was verified that the values of $F$ calculated $\left(F_{\text {calc. }}\right)$ were lower than the value of $F$ tabulated $\left(F_{\text {tab. }}\right)$ for the parameters $E_{\mathrm{sw}}$ and $\Delta E$, both linear. This indicates that the levels for the parameters $E_{\mathrm{sw}}$ and $\Delta E$ were studied in a satisfactory range (Table 4 ). In addition, the value of $F_{\text {calc. }}\left(\mathrm{MS}_{\text {lack of fit }} / \mathrm{MS}_{\text {pure error }}\right)$ was of 0.903 being

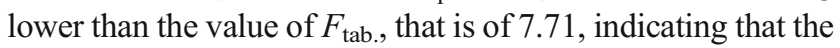
results are suited to the linear quadratic model, having a value of $R^{2}$ of 0.994 and $R^{2}$ adjusted of 0.988 .

Thus, the statistical model obtained from the Doehlert matrix is given by the following equation:

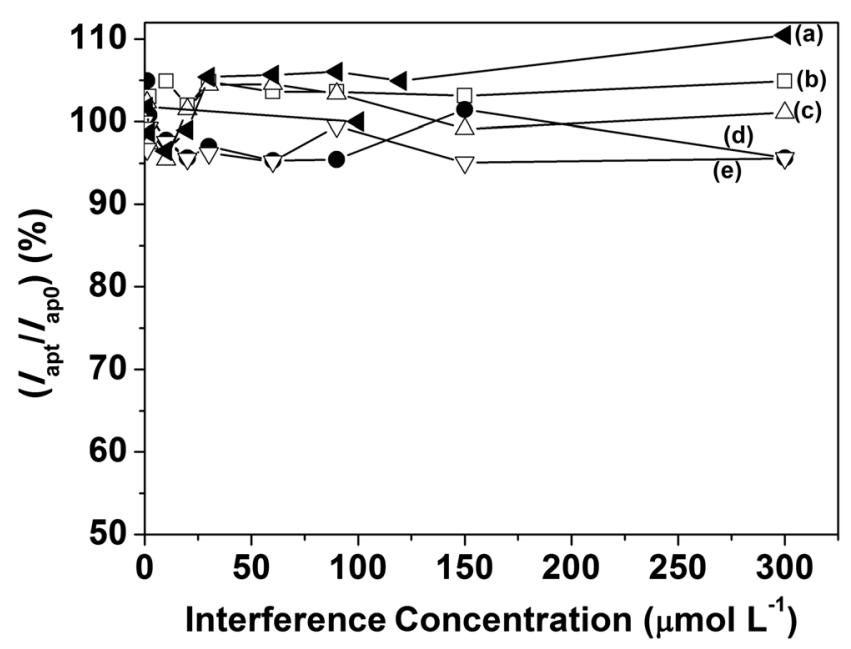

Fig. 7 Effect in the $I_{\text {ap }}$ for a concentration of $30.0 \mu \mathrm{mol} \mathrm{L}^{-1}$ of TRT in the presence of some substances in the urine in $0.10 \mathrm{~mol} \mathrm{~L}^{-1} \mathrm{~B}-\mathrm{R}$ buffer solution (pH 6.0). CR (a), UA (b), UR (c), GL (d), and AA (e)
Table 5 Recoveries of TRT in tap water samples using the GECE/MPsTo electrode

\begin{tabular}{lclc}
\hline Sample & Sample 1 & Sample 2 & Sample 3 \\
\hline Added $\left(\mu \mathrm{mol} \mathrm{L}{ }^{-1}\right)$ & 15.00 & 15.00 & 15.00 \\
Found $\left.(\mu \mathrm{mol} \mathrm{L})^{-1}\right)$ & $15.50 \pm 0.84$ & $14.80 \pm 0.96$ & $15.20 \pm 0.83$ \\
Recoveries $(\%)$ & 103.00 & 98.70 & 102.00 \\
$t_{\text {cal. }}$ & 0.93 & 0.34 & 0.45 \\
\hline
\end{tabular}

$t_{\text {crit. }}=4.30 ; n=3$

$\begin{aligned} \text { O.D. } & =0.505-0.0100 \times E_{\mathrm{sw}}-0.216 \times E_{\mathrm{sw}}{ }^{2}+0.0130 \\ & \times \Delta E-0.303 \times \Delta E^{2}-0.295 \times E_{\mathrm{sw}} \times \Delta E .\end{aligned}$

Therefore, the statistical model above was derived, so maximum values of $E_{\mathrm{sw}}(11.5 \mathrm{mV})$ and $\Delta E(36.2 \mathrm{mV})$ were obtained. In Fig. 5, the response surface from the Eq. 5 is shown.

\section{Analytical curve}

Figure 6 illustrates the square wave voltammograms obtained for the diuretic TRT from 0.500 to $99.8 \mu \mathrm{mol} \mathrm{L}^{-1}$ in $0.10 \mathrm{~mol} \mathrm{~L}^{-1} \mathrm{~B}-\mathrm{R}$ buffer solution ( $\mathrm{pH}$ 6.0) under optimized conditions. Good linear relationship was obtained in all concentration presenting the following linear relationship: $I_{\text {ap }}=(1.180 \pm 0.013) \times[$ TRT $]+(0.7 \pm 0.6) \times 10^{-7}\left(R^{2}=0.999\right)$ as shown in the insert of Fig. 6 . The limits of detection (L.D.) and quantitation (L.Q.) were calculated using the following equations: L.D. $=3 \mathrm{std} / m$ and L.Q. $=10 \mathrm{std} / m$, where std is the standard deviation of 10 square wave voltammograms only

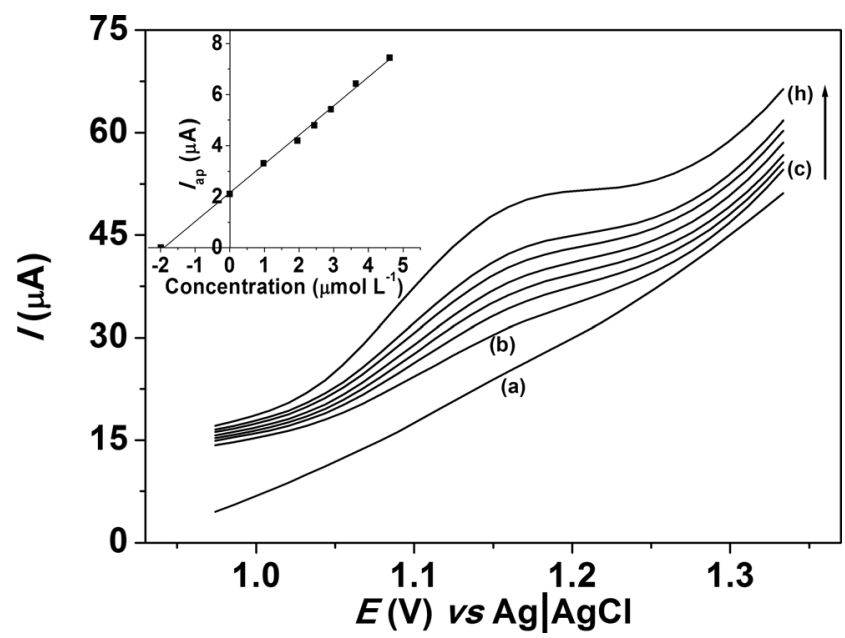

Fig. 8 Square wave voltammograms recorded for $0.10 \mathrm{~mol} \mathrm{~L}^{-1} \mathrm{~B}-\mathrm{R}$ buffer solution ( $\mathrm{pH}$ 6.0) for supporting electrolyte (a), addition of $2 \mathrm{~mL}$ of sample $(b)$, and successive standard additions of TRT in the concentrations of $0.980(c), 1.95(d), 2.44(\mathbf{e}), 2.92(f), 3.64(g)$, and $4.61 \mu \mathrm{mol} \mathrm{L}^{-1}(h)$ using the GECE/MPs-To. Insert: Respective analytical curve obtained for $I_{\text {ap }} v s$ [TRT]. f: $30 \mathrm{~Hz}, \Delta E: 36.2 \mathrm{mV}, E_{\mathrm{sw}}: 11.5 \mathrm{mV}$ 
with the supporting electrolyte $\left(0.100 \mathrm{~mol} \mathrm{~L}^{-1} \mathrm{~B}-\mathrm{R}\right.$ buffer solution $\mathrm{pH} 6.0$ ) and $m$ the slope of the curve. Thus, the values for L.D. and L.Q. were 1.47 and $4.91 \times 10^{-7} \mathrm{~mol} \mathrm{~L}^{-1}$, respectively.

The repeatability of the method was tested through 10 consecutive analyzes for TRT solution at concentrations of 1.50 and $80.0 \times 10^{-6} \mathrm{~mol} \mathrm{~L}^{-1}$, where the relative standard deviation was 4.10 and $3.24 \%$, respectively, indicating that the proposed electrode is not poisoned in consecutive tests since the solution is stirred between measurements.

\section{Interference study}

The influence of possible interfering compounds such as uric acid (UA), urea (UR), ascorbic acid (AA), glucose (GL), and creatinine (CR) on the peak currents recoveries of TRT determination as well as on the peak resolution was examined. Under optimized conditions, square wave voltammograms were recorded for a solution containing $30.0 \mu \mathrm{mol} \mathrm{L}^{-1}$ of TRT and the possible interfering in different concentrations comprising the range of 1.00 to $300 \mu \mathrm{mol} \mathrm{L}{ }^{-1}$. As can be seen in Fig. 7, the percentages between the $I_{\text {ap }}$ of the TRT in the presence of interference $\left(I_{\text {apt }}\right)$ about the $I_{\text {ap }}$ of the TRT $\left(I_{\text {ap0 }}\right)$ for substances UA (b), UR (c), GL (d), and AA (e) were in the range of 101-104, 95.0-104, 95.0-104, and 95.0-99.0\%, respectively, verifying that these substances showed no interference in $I_{\text {ap }}$ of the TRT in the concentration range studied. However for CR (a), no interference was observed for the concentration range of 1.00 to $120 \mu \mathrm{mol} \mathrm{L}{ }^{-1}$, where the percentage of $I_{\text {apt }} / I_{\text {ap } 0}$ was between 96.0 and $106 \%$. Nonetheless, for concentration of $300 \mathrm{mmol} \mathrm{L}^{-1}$ of $\mathrm{CR}$, a relationship between $I_{\text {apt }} / I_{\text {ap0 }}$ of $110 \%$ was observed, indicating that in higher concentrations, the $\mathrm{CR}$ can act as a possible interference in the determination of TRT diuretic.

\section{Application of the GECE/MPs-To to the analysis of TRT in human urine samples}

Firstly, the performance of the proposed sensor was tested in tap water samples to evaluate the method recovery. For this, tap water samples were spiked to $15.0 \mu \mathrm{mol} \mathrm{L}^{-1}$ TRT. The recovery was verified by the standard addition method, where the added and recovered values are shown in Table 5. As can be seen, for all samples, the recoveries were between 98.7 and $103 \%$. The calculated value of $t\left(t_{\text {calc }}\right)$ was smaller than $t$ tabulated $\left(t_{\text {tab. }}\right)$, indicating that there is significant difference at $95 \%$ confidence between the fortified and recovered concentration. In addition, the recoveries of TRT in tap water did not exceed $3.30 \%$ error, indicating good applicability of the method.

Afterwards, the applicability of the GECE/MPs-To to determine TRT in human urine sample was tested. As described in the experimental part (section "Urine samples"), an aliquot of spiked urine with $4.93 \mu \mathrm{mol} \mathrm{L}{ }^{-1}$ of TRT was added in the electrochemical cell without prior treatment of the sample. The respective voltammogram is shown in Fig. 8 before ("a" for supporting electrolyte and "b" for human urine sample) and after ( $\mathrm{c}$ to $\mathrm{h}$ ) successive standard additions of TRT. An excellent linear relationship was obtained, and a value of 4.97 $\pm 0.150 \mu \mathrm{mol} \mathrm{L}^{-1}$ was found (Fig. 8, insert), which represent $101 \%$ of recovery.

The method was validated by using LC-MS/MS where the urine sample was treated as previously described in section "Urine samples." The chromatographic peak employed for quantification was observed in the $t_{\mathrm{r} \text {. }}$ of $3.39 \mathrm{~min}$ which corresponds to the most intense transition monitored (first transition showed at Table 1). Beside the analyses of the sample by standard additions, the concentration found by LC-MS/MS technique was $5.20 \pm 0.18 \mu \mathrm{mol} \mathrm{L}{ }^{-1}$, representing $105 \%$ of recovery.

Calculating the Student's $t$ test (paired $t$ test), a value of 3.83 was found, where the calculated value is less than the value of $t_{\text {crit. }}$ (4.30) [45]. Thus, the results for the recovery of the TRT in the human urine sample by the proposed method showed no significant difference at $95 \%$ confidence compared to LC-MS/MS technique.

\section{Conclusion}

In this work, a simple and reliable electroanalytical method based on a graphite-epoxy composite electrode modified by tosyl-functionalized magnetic particles (GECE/MPs-To) for determination of the triamterene diuretic in human urine sample was proposed. After multivariate optimization of the inherent parameters of the square wave voltammetry, an analytical curve was constructed in wide linear range and low limit of detection plus excellent repeatability for different concentrations. The GECE/MPs-To was successfully applied in human urine sample where there was no significant difference when compared to LC-MS/MS technique. Finally, this work is an attractive method for environmentally friendly detection.

Acknowledgments The authors gratefully acknowledge the financial support from Fundação de Amparo à Pesquisa do Estado de São Paulo (FAPESP), CAPES, and CNPq.

\section{References}

1. Yang J, Park S-B, Yoon H-G, Huh Y-M, Haam S (2006) Preparation of poly $\varepsilon$-caprolactone nanoparticles containing magnetite for magnetic drug carrier. Int J Pharm 324:185-190

2. Hu FX, Neoh KG, Kang ET (2006) Synthesis and in vitro anticancer evaluation of tamoxifen-loaded magnetite/PLLA composite nanoparticles. Biomaterials 27:5725-5733 
3. Ma Z, Liu H (2007) Synthesis and surface modification of magnetic particles for application in biotechnology and biomedicine. China Part 5:1-10

4. Luo Y-L, Fan L-H, Xu F, Chen Y-S, Zhang C-H, Wei Q-B (2010) Synthesis and characterization of $\mathrm{Fe}_{3} \mathrm{O}_{4} / \mathrm{PPy} / \mathrm{P}(\mathrm{MAA}-\mathrm{co}-$ AAm) trilayered composite microspheres with electric, magnetic and $\mathrm{pH}$ response characteristics. Mater Chem Phys 120:590-597

5. Shahbazi F, Amani K (2014) Synthesis, characterization and heterogeneous catalytic activity of diamine-modified silica-coated magnetite-polyoxometalate nanoparticles as a novel magneticallyrecoverable nanocatalyst. Catal Commun 55:57-64

6. Shan Z, Li C, Zhang X, Oakes KD, Servos MR, Wu Q, Chen H, Wang X, Huang Q, Zhou Y, Yang W (2011) Temperature-dependent selective purification of plasmid DNA using magnetic nanoparticles in an RNase-free process. Anal Biochem 412:117-119

7. Liu JW, Zhang Y, Chen D, Yang T, Chen ZP, Pan SY, Gu N (2009) Facile synthesis of high-magnetization $\gamma$-Fe2O3/alginate/ silica microspheres for isolation of plasma DNA. Colloids Surf A: Physicochem Eng Aspects 341:33-39

8. Garcia J, Zhang Y, Taylor H, Cespedes O, Webb ME, Zhou D (2011) Multilayer enzyme-coupled magnetic nanoparticles as efficient reusable biocatalysts and biosensors. Nanoscale 3:3721-3730

9. Kong L, Lu X, Jin E, Jiang S, Bian X, Zhang W, Wang C (2009) Constructing magnetic polyaniline/metal hybrid nanostructures using polyaniline $/ \mathrm{Fe}_{3} \mathrm{O}_{4}$ composite hollow spheres as supports. J Solid State Chem 182:2081-2087

10. Heli H, Majdi S, Sattarahmady N, Parsaei A (2010) Electrocatalytic oxidation and sensitive detection of deferoxamine on nanoparticles of $\mathrm{Fe}_{2} \mathrm{O}_{3} @ \mathrm{NaCo}\left[\mathrm{Fe}(\mathrm{CN})_{6}\right]$-modified paste electrode. J Solid State Electrochem 14:1637-1647

11. Alizadeh T, Jamshidi F (2015) Synthesis of nanosized sulfatemodified $\alpha-\mathrm{Fe}_{2} \mathrm{O}_{3}$ and its use for the fabrication of all-solid-state carbon paste $\mathrm{pH}$ sensor. J Solid State Electrochem 19:1053-1062

12. Hu Y, Zhang Z, Zhang H, Luo L, Yao S (2012) Selective and sensitive molecularly imprinted sol-gel film-based electrochemical sensor combining mercaptoacetic acidmodified $\mathrm{PbS}$ nanoparticles with $\mathrm{Fe}_{3} \mathrm{O}_{4} @ \mathrm{Au}$-multi-walled carbon nanotubes-chitosan. J Solid State Electrochem 16:857-867

13. Yang S, Li G, Wang G, Deng D, Qu L (2015) A novel electrochemical sensor based on $\mathrm{Fe}_{2} \mathrm{O}_{3}$ nanoparticles/N-doped graphene for electrocatalytic oxidation of L-cysteine. J Solid State Electrochem. Doi:10.1007/s10008-015-2980-y

14. Pailleret A, Hien NTL, Thanh DTM, Deslouis C (2007) Surface reactivity of polypyrrole/iron-oxide nanoparticles: electrochemical and CS-AFM investigations. J Solid State Electrochemi 11:10131021

15. Lermo A, Fabiano S, Hernández S, Galve R, Marco M-P, Alegret S, Pividori MI (2009) Immunoassay for folic acid detection in vitamin-fortified milk based on electrochemical magneto sensors. Biosens Bioelectro 24:2057-2063

16. Mani V, Wu T-Y, Chen S-M (2014) Iron nanoparticles decorated graphene-multiwalled carbon nanotubes nanocomposite-modified glassy carbon electrode for the sensitive determination of nitrite. J Solid State Electrochem 18:1015-1023

17. Petcharoena K, Sirivat A (2012) Synthesis and characterization of magnetite nanoparticles via the chemical co-precipitation method. Mat Sci Eng B 177:421-427

18. Mahdaviana AR, Mirrahimib MA-S (2010) Efficient separation of heavy metal cations by anchoring polyacrylic acid on superparamagnetic magnetite nanoparticles through surface modification. Chem Eng J 159:264-271

19. Una B, Durmus Z, Kavas H, Baykal A, Toprak MS (2010) Synthesis, conductivity and dielectric characterization of salicylic acid- $\mathrm{Fe}_{3} \mathrm{O}_{4}$ nanocomposite. Mater Chem Phys 123:184-190

20. Liu X, Kaminski MD, Guan Y, Chen H, Liu H, Rosengart AJ (2006) Preparation and characterization of hydrophobic superparamagnetic magnetite gel. J Magn Magn Mater 306:248253

21. Bruce IJ, Taylor J, Todd M, Davies MJ, Borioni E, Sangregorio C, Sen T (2004) Synthesis, characterisation and application of silicamagnetite nanocomposites. J Magn Magn Mater 284:145-160

22. Asuha S, Suyala B, Siqintana X, Zhao S (2011) Direct synthesis of $\mathrm{Fe}_{3} \mathrm{O}_{4}$ nanopowder by thermal decomposition of $\mathrm{Fe}$-urea complex and its properties. J Alloy Compd 509:2870-2873

23. Laube T, Kergaravat SV, Fabiano SN, Hernández SR, Alegret S, Pividori MI (2011) Magneto immunosensor for gliadin detection in gluten-free foodstuff: Towards food safety for celiac patients. Biosens Bioelectro 27:46-52

24. Bagheri H, Afkhami A, Panahi Y, Khoshsafar H, Shirzadmehr A (2014) Facile stripping voltammetric determination of haloperidol using a high performance magnetite/carbon nanotube paste electrode in pharmaceutical and biological samples. Mat Sci Eng C 37:264-270

25. Yin H, Zhou Y, Ma Q, Ai S, Chen Q, Zhu L (2010) Electrocatalytic oxidation behavior of guanosine at graphene, chitosan and $\mathrm{Fe}_{3} \mathrm{O}_{4}$ nanoparticles modified glassy carbon electrode and its determination. Talanta 82:1193-1199

26. Deventer K, Pozo OJ, Eenoo PV, Delbeke FT (2009) Qualitative detection of diuretics and acidic metabolites of other doping agents in human urine by high-performance liquid chromatography-tandem mass spectrometry: Comparison between liquid-liquid extraction and direct injection. J Chromatogr A 1216:5819-5827

27. Goebel C, Trout GJ, Kazlauskas R (2004) Rapid screening method for diuretics in doping control using automated solid phase extraction and liquid chromatography-electrospray tandem mass spectrometry. Anal Chim Acta 502:65-74

28. The World Anti-Doping Code: The 2014 prohibited list (2015). http://list.wadaama.org/wp-content/uploads/2013/11/2014Prohibited-List-ENGLISH-FINAL.pdf. Accessed 25 Sept 2015

29. Maher HM, Youssef RM, El-Kimary EI, Hassana EM, Barary MA (2012) Bioavailability study of triamterene and xipamide using urinary pharmacokinetic data following single oral dose of each drug or their combination. J Pharmaceut Biomed 61:78-85

30. Tabrizi AB, Naini S, Parnian K, Mohammadi S, Zad FE, Anvarian SP, Abdollahi A (2014) Determination of triamterene in human plasma and urine after its cloud point extraction. Quim Nov. 37: 1182-1187

31. Sanchez FG, Diaz AN, Guerrero MML (2015) Time-Resolved Spectroscopy for Selective Determination of Fluorescent Diuretics. Spectrosc Lett 48:481-486

32. Brunelli C, Bicchi C, Stilo AD, Salomone A, Vincenti M (2006) High-speed gas chromatography in doping control:Fast$\mathrm{GC}$ and fast-GC/MS determination ofb-adrenoceptor ligands and diuretics. J Sep Sci 29:2765-2771

33. Nezhadali A, Mojarrab M (2015) Fabrication of an electrochemical molecularly imprinted polymer triamterene sensor based on multivariate optimization using multi-walled carbon nanotubes. J Electroanal Chem 744:85-94

34. Ensafi AA, Hajian R (2008) Determination of Losartan and Triamterene in Pharmaceutical Compounds and Urine Using Cathodic Adsorptive Stripping Voltammetry. Anal Sci 24:14491454

35. Merás ID, Mansilla AE, López FS, Gómez MJR (2002) Determination of triamterene and leucovorin in biological fluids by UV derivative-spectrophotometry and partial leastsquares (PLS-1) calibration. J Pharmaceut Biomed 27:81-90

36. Lermo A, Zacco E, Barak J, Delwiche M, Campoy S, Barbé J, Alegret S, Pividori MI (2008) Towards Q-PCR of pathogenic bacteria with improved electrochemical double-tagged genosensing detection. Biosens Bioelectro 23:1805-1811

37. Erdem A, Pividori MI, Lermo A, Bonanni A, Valle M, Alegret S (2006) Genomagnetic assay based on label-free electrochemical 
detection using magneto-composite electrodes. Sensor Actuat BChem 114:591-598

38. Murray GJ, Danaceau JP (2009) Simultaneous extraction and screening of diuretics, beta-blockers, selected stimulants and steroids in human urine by HPLC-MS/MS and UPLC-MS/MS. J Chromatogr B 877:3857-3864

39. Bard AJ, Faulkner LR (2001) Electrochemical methods: fundamentals and applications, 2nd edn. Wiley, New York

40. Sartori ER, Takeda HH, Fatibello-Filho O (2011) Glassy Carbon Electrode Modified with Functionalized Carbon Nanotubes Within a Poly(allylamine hydrochloride) Film for the Voltammetric Determination of Sulfite in Foods. Electroanal 23:2526-2533

41. Neto BB, Scarminio IS, Bruns RE (2010) Como fazer experimentos, fourth edn. Bookman, Brazil
42. Ferreira SLC, Santos WNL, Quintella CM, Neto BB, BosqueSendra JM (2004) Doehlert matrix: a chemometric tool for analytical chemistry - review. Talanta 63:1061-1067

43. Hudari FF, Duarte EH, Pereira AC, Dall'Antonia LH, Kubota LT, Tarley CRT (2013) Voltammetric method optimized by multiresponse assays for the simultaneous measurements of uric acid and acetaminophen in urine in the presence of surfactant using MWCNT paste electrode. J Electroanal Chem 696:52-58

44. Jesus RM, Silva LOB, Castro JT, Neto ADA, Jesus RM, Ferreira SLC (2013) Determination of mercury in phosphate fertilizers by cold vapor atomic absorption spectrometry. Talanta 106:293-297

45. Miller JC, Miller JN (1988) Statistics for analytical chemistry, 2nd edn. Ellis Horwood Limited, England 